\title{
Synthesis, characterization, and field-effect performance of the halogenated indolone derivatives
}

Congyuan Wei ${ }^{\ddagger a}$, Jiabin Zou ${ }^{\ddagger b}$, Rui Zhu' ${ }^{a}$, Jianyao Huang ${ }^{c}$, Dong Gao ${ }^{c}$, Liping Wang ${ }^{\mathrm{b}}$ *, Weifeng

Zhang ${ }^{\mathrm{c},}$, , Yi Liao ${ }^{\mathrm{a}, *}$, Gui Yu $u^{\mathrm{c}, *}$

${ }^{a}$ Department of Chemistry, Capital Normal University, Beijing 100048, P. R. China

${ }^{\mathrm{b}}$ School of Material Science and Engineering, University of Science and Technology

Beijing, Beijing 100083, P.R. China

${ }^{\mathrm{c}}$ Beijing National Laboratory for Molecular Sciences, Institute of Chemistry, Chinese Academy of Sciences, Beijing 100190, P. R. China

To whom correspondence should be addressed. E-mail: yliao@cnu.edu.cn; lpwang@mater.ustb.edu.cn; zhangwf@iccas.ac.cn; yugui@iccas.ac.cn 
ABSTRACT: In this paper we present the design and synthesis of three $\pi$-extended indolone derivatives,

namely (3Z,3'Z)-3,3'-((5,5'-((E)-ethene-1,2-diyl)bis(thiophene-2,5-diyl))bis(methanylylidene) )bis(1-octylindolin-2-one) (3a), (3Z,3'Z)-3,3'-((5,5'-((E)-ethene-1,2-diyl)bis(thiophene-2,5-diyl))bis(methanylylidene) )bis(5-fluoro-1-octylindolin-2-one) and (3Z,3'Z)-3,3'-((5,5'-((E)-ethene-1,2-diyl)bis(thiophene-2,5-diyl))bis(methanylylidene) )bis(5-chloro-1-octylindolin-2-one (3c), with (E)-1,2-di(thiophen-2-yl)ethene as the donor and indolin-2-ones as the acceptors. All of the three acceptor-donor-acceptor type molecules have high conjugations and planar energy-minimized conformations, which are beneficial to forming ordered molecular packing and facilitating charge transport in thin films. Additionally, to study the effect of halogenation, fluorine and chlorine atoms were introduced in terms of microscale and mesoscale molecular engineering. $\mathbf{3 b}$ and $\mathbf{3 c}$ show obviously different feasures of crystalline tendencies and morphologies compared with those of 3a. Organic field-effect transistors based on the three small molecules display typical p-channel charge transport characteristics under ambient conditions. Fluorinated $\mathbf{3 b}$ affords the highest mobility of $0.1 \mathrm{~cm}^{2} \mathrm{~V}^{-1} \mathrm{~s}^{-1}$ among the three analogues, demonstrating that fluorination is a useful strategy to optimize the solid-state arrangement and device performances.

Keywords: Donor-acceptor compound; Mobility; Indole-2-one; Organic field-effect transistors 


\section{Introduction}

Organic semiconductors have been drawing extensive attention as promising candidates for flexible opto-electronics in recent years [1-3]. Development of novel semiconducting materials enable a new generation of low-cost, large-area applications in numerous electronic devices such as radio frequency identification tags, smart cards, electronic papers, displays, and sensors[4-6]. During the last decades, there has been considerable progress in small-molecular and polymeric semiconductors. A variety of both classes of $\pi$-conjugated materials have been synthesized and applied in organic field-effect transistors (OFETs) with charge carrier mobilities higher than that of amorphous silicon $\left(\begin{array}{cccc}1 & \mathrm{~cm}^{2} & \mathrm{~V}^{-1} & \mathrm{~s}^{-1}\end{array}\right)$ [7, 8]. Meanwhile, structure-property relationships pertaining to organic semiconductors have been put forward and reviewed, for example, heteroatom effect $[9,10]$, molecular symmetry [11], and alkyl side chains [12-14]. Moreover, some design strategies beyond molecular formula have also been concluded such as molecular size/weight [15] and impurities [16, 17]. However, they are still not enough in digging the structure-property relationships with the aim of developing high-performance organic semiconductors for large-scale applications.

For small molecular semiconductors, acenes and heteroacenes, especially thienoacenes, have been intensively studied in recent years [18-20]. These small molecule materials tend to afford high carrier mobilities, which are ascribed to suitable HOMO energy levels, reorganization energies and orderly molecular packing in solid states [21]. However, these fused heteroacenes pose daunting synthetic 
challenges, and cannot readily incorporate as building blocks into $\pi$-conjugated backbones of polymeric semiconductors. Thus, developing new building blocks that are facilely synthesized are meaningful for both small molecular and polymeric semiconductors. At present, the third generation polymers, donor-acceptor (D-A) copolymers, have been largely investigated in OFETs [22]. One of the important reasons is that the opto-electronic properties of the polymer could be fine-tuned by modifying the chemical structures of either electron-rich or electron-deficient units. Moreover, this class of polymers often own weakly polarized state along their polymer backbones, which will promote the charge injection at the electrode/semiconductor interface and facilitate the charge transport in the corresponding OFET devices [23]. D-A type small molecules have also been developed as the prototype semiconductor for further rational design [24]. Among these molecules, symmetric small molecules have greater potential because not only could they intrinsically behave as high-performance semiconductors themselves as a result of the highly ordered molecular packing in thin films, but could be used as building blocks as well through slight modification in chemical structures.

To design such small molecules, backbone planarity is typical concern due to the enhancement of $\pi$-orbital overlaps promoting close stacking and charge transporting. Some weak noncovalent interactions have been purposefully introduced to obtain planar structure. A variety of potential interactions, including $S \cdots O, S \cdots F$, and H-bonds, etc. are named as "conformational locks" [25]. Meanwhile, intermolecular interactions have also been enhanced between neighbouring molecules and even act 
as charge transport channels [26]. Thus, these interactions are essential in constructing high-performance semiconducting materials. Halogenation proved to be an efficient strategy to lower frontier molecular orbital energy levels and induce face-to-face $\pi$-stacking, providing a powerful tool for molecular engineering [27, 28]. The large dipole of carbon-halogen bonds depletes the electron density of $\pi$-frameworks, subsequently affecting the stacking interactions. Herein, we have designed and synthesized a series of A-D-A type small molecules with or without halogens, (3Z,3'Z)-3,3'-((5,5'-((E)-ethene-1,2-diyl)bis(thiophene-2,5-diyl))bis(methanylylidene) )bis(1-octylindolin-2-one) (3Z,3'Z)-3,3'-((5,5'-((E)-ethene-1,2-diyl)bis(thiophene-2,5-diyl))bis(methanylylidene) )bis(5-fluoro-1-octylindolin-2-one) and (3Z,3'Z)-3,3'-((5,5'-((E)-ethene-1,2-diyl)bis(thiophene-2,5-diyl))bis(methanylylidene) )bis(5-chloro-1-octylindolin-2-one (3c), in which indolin-2-ones and (E)-1,2-di(thiophen-2-yl)ethene (TVT) serves as the acceptor and donor unit, respectively. Compared with previously reported analogues containing thieno[3,2-b]thiophene (TT) or 2,2'-bithiophene (BT), TVT has planar energy-minimized conformation and excellent rigidity, allowing for the enhanced planarity of the molecular skeleton. Additionally, the introduction of TVT unit is in favour of the aggregation because the bulky alkyl chains are separated farther due to the longer conjugation length. This class of $\pi$-conjugated backbone could be utilized to further synthesize semiconducting copolymers through minor modifications. The presence of $\mathrm{S} \cdots \mathrm{O}$ conformational locks is in favour of maintaining planar structures. 
Theoretical calculation results show that these molecules own highly delocalized frontier orbitals. With the introduction of halogen atoms at the 5-position of indolin-2-one unit, the two halogenated small molecule semiconductors show different charge transport characteristics. Especially, the fluorine substituted $\mathbf{3 b}$, exhibited enhanced field-effect properties with the highest hole mobility of $0.10 \mathrm{~cm}^{2}$ $\mathrm{V}^{-1} \mathrm{~s}^{-1}$, which is much higher than those of 3a and 3c. The results highlight the promising potentials of fluorinated building blocks in constructing small molecular and polymeric semiconductors.

\section{Experimental section}

\subsection{Materials and methods}

The chemicals and catalysts were purchased from ACROS, Sigma-Aldrich, and Sinopharm Chemical Reagent CO., Ltd. The solvents were freshly distilled according to standard methods under nitrogen atmosphere. The reactions were performed in Schlenk flask under nitrogen atmosphere.

Nuclear magnetic resonance (NMR) spectra were obtained in deuterated chloroform $\left(\mathrm{CDCl}_{3}\right)$ with a Bruker AVANCE 300 spectrometer. EI-MS and high-resolution EI-MS were recorded on a Shimadzu QP 2010 gas chromatograph mass spectrometer. MALDI-TOF mass spectrometric measurements were performed on Bruker Autoflex III type MALDI-TOF. HR-MALIDIs were acquired on Bruker Solarix type Fourier transform ion cyclotron resonance mass spectrometer. UV-vis absorption spectra were measured on a Jasco V-570 type spectrophotometer. Cyclic voltammetry $(\mathrm{CV})$ experiments were conducted on an electrochemistry workstation 
(CHI660C, Chenhua Shanghai) using a three-electrode cell. Thermogravimetric analysis (TGA) were carried out on DTG-60 instrument under nitrogen flow, heating from room temperature (RT) to $550{ }^{\circ} \mathrm{C}$, with a heating rate of $10{ }^{\circ} \mathrm{C} / \mathrm{min}$. The $\mathrm{XRD}$ were tested on Polycrystalline diffractometer (PANalytical).

All theoretical calculations were carried out with the Gaussian 09 package. The geometry structure for $\mathbf{3 a}, \mathbf{3 b}$ and $\mathbf{3 c}$ were optimized by performing density functional theory (DFT) calculations at the B3LYP level with a 6-31+G (d) basis set.

\subsection{Device Fabrication and Characterization}

Bottom gate/bottom contact devices using $\mathrm{n}^{++}-\mathrm{Si} / \mathrm{SiO}_{2}$ substrates $(300 \mathrm{~nm})$ were fabricated to investigate the charge transport properties. The Au was used as the source-drain electrodes, and they were prepared by the photolithography technique. The next processes are as follows: the $\mathrm{SiO}_{2}$ substrates were washed in acetone, deionized water, and ethanol. Then, the substrates were dried in atmosphere at $60{ }^{\circ} \mathrm{C}$. Octadecyltrichlorosilane (OTS) self-assembled layer was formed by using OTS in vacuum at $120{ }^{\circ} \mathrm{C}$. The treated substrates were rinsed with hexane, ethanol and chloroform. After that, a layer of $\mathbf{3 a}(\mathbf{3 b}$ or $3 \mathbf{c})$ thin film was deposited on the OTS-modified $\mathrm{SiO}_{2}$ substrates by spin-coating a solution of the corresponding compound in chloroform $(10 \mathrm{mg} / \mathrm{mL})$ with a speed of $1400 \mathrm{rpm}$ for 60 seconds. To optimize the FET performance, the devices were annealed at different temperature. The devices were heated in air directly on a hotplate and the FET characteristics of the devices were tested directly in air with a Keithley 4200 SCS semiconductor parameter analyser. The mobility was calculated in the saturated regime using the following 
equation:

$$
I_{\mathrm{DS}}=(W / 2 L) C_{\mathrm{i}} \mu\left(V_{\mathrm{GS}}-V_{\mathrm{TH}}\right)^{2}
$$

in which $W / L$ is the ratio of the channel width/length, $C_{\mathrm{i}}$ is the insulator capacitance per unit area, $V_{\mathrm{GS}}$ and $V_{\mathrm{TH}}$ corresponds to the gate voltage and threshold voltage, respectively.

\subsection{Synthetic procedures}

(3Z,3'Z)-3,3'-((5,5'-((E)-ethene-1,2-diyl)bis(thiophene-2,5-diyl))bis(methanylylide ne))bis(indolin-2-one) (2a)

To a suspension of $(E)-5,5^{\prime}$-(ethene-1,2-diyl)dithiophene-2-carbaldehyde $(0.30 \mathrm{~g}$, $1.21 \mathrm{mmol})$ and 1,3-dihydro-2H-indol-2-one (1a, $0.32 \mathrm{~g}, 2.42 \mathrm{mmol})$ in methanol (30 $\mathrm{mL}$ ) was added catalytic piperidine under argon. The reaction mixture was heated to reflux and stirred overnight. The mixture was allowed to cool to room temperature, filtered and washed with methanol. The residual solvent was removed under vacuum. The crude product was used for the next step without further purification $(0.56 \mathrm{~g}$, 96.7\%). HR-MALDI calcd for $\mathrm{C}_{28} \mathrm{H}_{18} \mathrm{~N}_{2} \mathrm{O}_{2} \mathrm{~S}_{2}$ : 478.0804; found 478.0807.

(3Z,3'Z)-3,3'-((5,5'-((E)-ethene-1,2-diyl)bis(thiophene-2,5-diyl))bis(methanylylide ne))bis(5-fluoroindolin-2-one) (2b)

Compound 2b was prepared in the same way of $\mathbf{2 a}$, with

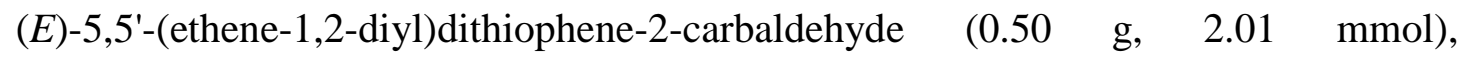
5-fluoroindolin-2-one (1), $0.61 \mathrm{~g}, 4.03 \mathrm{mmol})$ and a catalytic amount of piperidine (yield: 0.94g, 91\%). HR-MS calcd for $\mathrm{C}_{28} \mathrm{H}_{16} \mathrm{~F}_{2} \mathrm{~N}_{2} \mathrm{O}_{2} \mathrm{~S}_{2}$ : 514.0621; found 514.0629. (3Z,3'Z)-3,3'-((5,5'-((E)-ethene-1,2-diyl)bis(thiophene-2,5-diyl))bis(methanylylide 
ne))bis(5-chloroindolin-2-one) (2c)

Compound $\mathbf{2 c}$ was prepared in the same way of $\mathbf{2 a}$, with

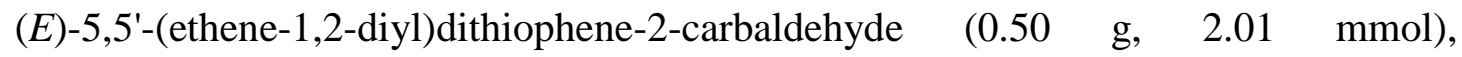
5-chloroindolin-2-one (1c, $0.68 \mathrm{~g}, 4.03 \mathrm{mmol})$ and a little amount of piperidine (yield: 1.03g, 93\%). HR-MS calcd for $\mathrm{C}_{28} \mathrm{H}_{16} \mathrm{Cl}_{2} \mathrm{~N}_{2} \mathrm{O}_{2} \mathrm{~S}_{2}$ : 546.0030; found 546.0040.

(3Z,3'Z)-3,3'-((5,5'-((E)-ethene-1,2-diyl)bis(thiophene-2,5-diyl))bis(methanylylide ne))bis(1-octylindolin-2-one) (3a)

To a mixture of $\mathbf{2 a}(0.53 \mathrm{~g}, 1.11 \mathrm{mmol}), \mathrm{K}_{2} \mathrm{CO}_{3}(0.46 \mathrm{~g}, 3.33 \mathrm{mmol})$ and a catalytic amount of 18-crown-6 in DMF (25 mL) was added 1-bromooctane (0.86 g, 4.44 mmol) under argon. The mixture was stirred at $110{ }^{\circ} \mathrm{C}$ for $24 \mathrm{~h}$. The mixture was extracted with ethyl acetate, washed with water and brine, dried with anhydrous $\mathrm{MgSO}_{4}$ and filtered. The solvent was removed under reduced pressure and the residues were purified by silica gel chromatography to obtain the final product as a dark violet solid (71 mg, 9.1\%). ${ }^{1} \mathrm{H} \mathrm{NMR}\left(300 \mathrm{MHz}, \mathrm{CDCl}_{3}, \delta\right): 7.64$ (s, 2H), 7.57 (d, $2 \mathrm{H}, J=3.9 \mathrm{~Hz}), 7.52(\mathrm{~d}, 2 \mathrm{H}, J=7.5 \mathrm{~Hz}), 7.35(\mathrm{~s}, 2 \mathrm{H}), 7.26-7.24(\mathrm{~m}, 2 \mathrm{H}), 7.10(\mathrm{~d}$, $2 \mathrm{H}, J=3.9 \mathrm{~Hz}), 7.05(\mathrm{t}, 2 \mathrm{H}, J=7.5 \mathrm{~Hz}), 6.86(\mathrm{~d}, 2 \mathrm{H}, J=7.8 \mathrm{~Hz}), 3.82(\mathrm{t}, 4 \mathrm{H}, J=7.5$ $\mathrm{Hz}), 1.74(\mathrm{~m}, 4 \mathrm{H}), 1.38-1.27(\mathrm{~m}, 20 \mathrm{H}), 0.87(\mathrm{t}, 6 \mathrm{H}, J=6.9 \mathrm{~Hz}) .{ }^{13} \mathrm{C} \mathrm{NMR}(75 \mathrm{~Hz}$, $\left.\mathrm{CDCl}_{3}, \delta\right): 166.27,149.85,141.51,138.31,137.47,128.35,127.67,124.09,123.77$ $121.50,121.20,118.76,108.22,39.99,31.82,29.37,29.23,27.86,27.15,22.65,14.11$. HR-MALDI calcd for $\mathrm{C}_{44} \mathrm{H}_{50} \mathrm{~N}_{2} \mathrm{O}_{2} \mathrm{~S}_{2} \mathrm{Na}$ : 725.3206; found $725.3203[\mathrm{M}+\mathrm{Na}]^{+}$. (3Z,3'Z)-3,3'-((5,5'-((E)-ethene-1,2-diyl)bis(thiophene-2,5-diyl))bis(methanylylide ne))bis(5-fluoro-1-octylindolin-2-one) (3b) 
The procedure of $\mathbf{3 b}$ is the same as $\mathbf{3 a}$, using $\mathbf{2 b}(0.94 \mathrm{~g}, 1.83 \mathrm{mmol}), \mathrm{K}_{2} \mathrm{CO}_{3}(0.76$ g, $5.49 \mathrm{mmol}$ ) and a catalytic amount of 18-crown-6 in DMF (30 mL) was added 1-bromooctane (1.42 g, $7.31 \mathrm{mmol}$ ) (yield: $250 \mathrm{mg}, 18.5 \%) .{ }^{1} \mathrm{H}$ NMR (300 MHz, $\left.\mathrm{CDCl}_{3}, \delta\right): 7.58(\mathrm{~d}, 2 \mathrm{H}, J=3.9 \mathrm{~Hz}), 7.55(\mathrm{~s}, 2 \mathrm{H}), 7.31(\mathrm{~s}, 2 \mathrm{H}), 7.21-7.17(\mathrm{~m}, 2 \mathrm{H})$, $7.08(\mathrm{~d}, 2 \mathrm{H}, J=3.9 \mathrm{~Hz}), 6.94-6.90(\mathrm{~m}, 2 \mathrm{H}), 6.75-6.71(\mathrm{~m}, 2 \mathrm{H}), 3.78(\mathrm{t}, 4 \mathrm{H}, J=7.5$ $\mathrm{Hz}), 1.75-1.66(\mathrm{~m}, 4 \mathrm{H}), 1.38-1.27(\mathrm{~m}, 20 \mathrm{H}), 0.87(\mathrm{t}, 6 \mathrm{H}, J=6.9 \mathrm{~Hz}) .{ }^{13} \mathrm{C} \mathrm{NMR}(75 \mathrm{~Hz}$ $\left.\mathrm{CDCl}_{3}, \delta\right): 166.13,160.35,157.18,150.49,139.13,137.20,128.72,127.82,125.37$ $123.93,120.68,114.30,108.69,106.45,40.09,31.79,29.35,29.21,27.78,27.12$, 22.63, 14.09. MALDI-TOF: $\mathrm{m} / \mathrm{z}$ 738.4[M $\left.\mathrm{M}^{+}\right]$, HR-MALDI calcd for $\mathrm{C}_{44} \mathrm{H}_{48} \mathrm{~F}_{2} \mathrm{~N}_{2} \mathrm{O}_{2} \mathrm{~S}_{2} \mathrm{Na}$ : 761.3017; found $761.3014[\mathrm{M}+\mathrm{Na}]^{+}$.

(3Z,3'Z)-3,3'-((5,5'-((E)-ethene-1,2-diyl)bis(thiophene-2,5-diyl))bis(methanylylide ne))bis(5-chloro-1-octylindolin-2-one) (3c)

The procedure of $\mathbf{3 c}$ is the same as $\mathbf{3 a}$, using $\mathbf{2 c}(1.00 \mathrm{~g}, 1.83 \mathrm{mmol}), \mathrm{K}_{2} \mathrm{CO}_{3}(0.76 \mathrm{~g}$, $5.49 \mathrm{mmol})$ and a catalytic amount of 18 -crown-6 in DMF $(30 \mathrm{~mL})$ was added 1-bromooctane (1.42 g, $7.31 \mathrm{mmol}$ ) (yield: $140 \mathrm{mg}, 9.9 \%) .{ }^{1} \mathrm{H}$ NMR (300 MHz, $\left.\mathrm{CDCl}_{3}, \delta\right): 7.59(\mathrm{~m}, 4 \mathrm{H}), 7.34(\mathrm{~s}, 2 \mathrm{H}), 7.21(\mathrm{~m}, 2 \mathrm{H}), 7.10(\mathrm{~d}, 2 \mathrm{H}, J=4.2 \mathrm{~Hz})$, 6.96-6.92 (m, 2H), 6.77-6.73(m, 2H), $3.79(\mathrm{t}, 4 \mathrm{H}, J=7.5 \mathrm{~Hz}), 1.76-1.67(\mathrm{~m}, 4 \mathrm{H})$, 1.45-1.27(m, 20H), $0.87(\mathrm{t}, 6 \mathrm{H}, J=6.9 \mathrm{~Hz}) .{ }^{13} \mathrm{C} \mathrm{NMR}\left(75 \mathrm{~Hz}, \mathrm{CDCl}_{3}, \delta\right): 165.91$, $150.57,139.80,139.06,137.25,128.76,127.89,127.80,127.01,125.54,123.94$, $120.01,118.93,109.04,40.20,31.80,29.34,29.22,27.81,27.12,22.64,14.10$. MALDI-TOF: m/z 771.6 [M+], HR-MALDI calcd for $\mathrm{C}_{44} \mathrm{H}_{48} \mathrm{Cl}_{2} \mathrm{~N}_{2} \mathrm{O}_{2} \mathrm{~S}_{2} \mathrm{Na}$ : 793.2426; found $793.2428[\mathrm{M}+\mathrm{Na}]^{+}$. 


\section{Results and discussion}

\subsection{Synthesis}

The synthetic routes of the three molecules, $\mathbf{3 a}, \mathbf{3 b}$ and $\mathbf{3 c}$, are shown in Scheme 1. The starting material was synthesized according to the literature reported [29]. A following Knoevenagel reaction was conducted between 1a-c and (E)-5,5'-(ethene-1,2-diyl)dithiophene-2-carbaldehyde to afford 2a-c, respectively. The target molecules were obtained by alkylation reaction of $\mathbf{2 a - c}$ in less than $20 \%$ yield respectively. The low yield could be ascribed to the low purity of 2a-c, which is almost insoluble in common organic solvents, thus difficult to purify in the reaction steps. The chemical structures of the final products and intermediates were determined by MALDI-TOF or EI-MS, ${ }^{1} \mathrm{H}$ NMR, ${ }^{13} \mathrm{C}$ NMR and high resolution MALDI.

\subsection{Theoretical calculation}

The DFT method at the B3LYP/6-31+G (d) level was performed to gain deep insight into the electronic and structural features of the three compounds. The distribution of HOMOs and LUMOs of all the compounds are shown in Fig. 1. To simplify the calculation, the long octyl group was replaced with methyl group. Apparently, energy-minimized geometries of all the molecules have good planarity as expected (the lateral diagrams are shown in Fig S1). The HOMOs and LUMOs of all

the three compounds delocalize all over the backbone, which is beneficial to $\pi$-overlaps between the molecules. Generally, halogen substituents behave as both $\sigma$-acceptors and $\pi$-donors [30]. Substitution at 5-position of indolone greatly reduces 
the $\pi$-donating character, therefore leading to dominating stabilization of frontier molecular orbitals by about 0.17 and $0.19 \mathrm{eV}$ for fluorine and chlorine substitution, respectively. Note that chlorinated 3c possess deeper HOMO and LUMO energies than fluorinated DITVT-5F, demonstrating that the empty $3 \mathrm{~d}$ orbitals of chlorine can accommodate more electron density than fluorine [31, 32]. This trend has also been observed in other halogenated acenes. The HOMO-LUMO bandgaps also decreased by substitution of halides compared with that of the unsubstituted parent compound, implying redshifts in absorption spectra. S $\cdots O$ contacts are confirmed by the energy-minimized conformation, yielding a significantly short $\mathrm{S} \cdots \mathrm{O}$ distance of ca. $2.79 \AA$ (sum of Van der Waal radii is $3.32 \AA$ ). The presence of noncovalent $\mathrm{S} \cdots \mathrm{O}$ interactions enforce more planar molecular skeletons, which could promote $\pi$-ordering in the solid states.

In an attempt to elucidate the substituent effect of halogen atoms on spectral features, we performed time-dependent density functional theory (TD-DFT) calculations to study the vertical excited state transitions. 3a presents two main vertical transitions at 2.1359 and $2.7086 \mathrm{eV}$ with oscillator strengths of 1.83 and 0.24 , respectively. The low-energy one is the HOMO to LUMO transition, and the high-energy one is a combination of HOMO-3 to LUMO+1 and HOMO-2 to LUMO. The large oscillator strength of the low-energy transition indicates the presence of peak overlap. 3b and 3c exhibit similar spectral signatures, although the second transition is only the HOMO-2 to LUMO transition. The lowest-energy singlet transition shifts from $583.8(2.1237 \mathrm{eV})$ to $584.3 \mathrm{~nm}(2.1218 \mathrm{eV})$ in changing the 
halogen atoms from $\mathrm{F}$ to $\mathrm{Cl}$. The oscillator strengths of these transitions are 1.75 and 1.83 for $\mathbf{3 b}$ and $\mathbf{3 c}$, respectively. These results indicate that halogenation redshifts the absorption spectra.

\subsection{Optical properties}

The UV-vis absorption spectra of all the compounds in dilute chloroform solution and thin film are shown in Fig. 2 and the results are listed in Table 1. All the three compounds display broad, single-band absorption spectra, which are attributed to HOMO-LUMO singlet transitions, as are evident from the TD-DFT calculations. Generally, similar low-energy transitions of previously reported D-A type molecules are attributed to intramolecular charge transfer. Compared with $\mathbf{3 a}, \mathbf{3 b}$ and $\mathbf{3 c}$ show slightly red-shifted absorption profiles with the maximum absorption peaks at 522 and $530 \mathrm{~nm}$, respectively. The changes of absorption spectra in solutions could be attributed to the substitution of $\mathrm{F}$ and $\mathrm{Cl}$ atoms, which is consistent with the calculation results. Their thin film absorption spectra of $\mathbf{3 a}, \mathbf{3 b}$ and $\mathbf{3 c}$ obviously red-shift and become broader in comparison with those in solutions, indicating the formation of $J$-aggregates in the solid state. For instance, the maximum absorption peak of 3a red-shifts from $516 \mathrm{~nm}$ in solution to $530 \mathrm{~nm}$ in the thin-film. The optical bandgaps $\left(E_{\mathrm{opt}}^{\mathrm{g}}\right)$, calculated from absorption cut-off value of thin film, are estimated to be $1.88 \mathrm{eV}, 1.81 \mathrm{eV}, 1.85 \mathrm{eV}$ for $\mathbf{3 a}, \mathbf{3 b}$ and $\mathbf{3 c}$, respectively. Additionally, the absorption spectra of the $\mathbf{3 a}$ and $\mathbf{3 b}$ thin films show a shoulder peak at 595 and 617 nm, respectively, which are attributed to vibronic signatures. Therefore, the introduction of halogen atoms to the $\mathbf{3 a} \pi$-conjugated skeleton could afford 
significant effects on tuning the optical and molecular aggregation behaviors.

\subsection{Electrochemical and thermal properties}

Fig. 3 shows the cyclic voltammograms of $\mathbf{3 a}, \mathbf{3 b}$ and $\mathbf{3 c}$ in chloroform with ferrocene as the internal standard. The electrochemical properties were tested under argon with a glassy carbon electrode as the working electrode, Pt wire as the counter electrode, an $\mathrm{Ag} / \mathrm{AgCl}$ electrode as the reference electrode, and a solution of n-Bu4NPF6 $(0.1 \mathrm{M})$ in chloroform as the electrolyte. All the potentials were calibrated using the redox couple of $\mathrm{Fc} / \mathrm{Fc}^{+}$, which was assumed to have the absolute energy level of $-4.80 \mathrm{eV}$ under vacuum. Their highest occupied molecular orbital (HOMO) and lowest unoccupied molecular orbital (LUMO) energy levels were estimated based on the respective onset oxidation $\left(\mathrm{E}_{\mathrm{oxd}}{ }^{\text {onset }}\right)$ and reduction potentials $\left(E_{\text {red }}{ }^{\text {onset }}\right)$ according to the equation of $E_{\mathrm{HOMO}}=-\left(E_{\text {oxd }}{ }^{\text {onset }}-E_{\text {(ferrocene })^{\text {onset }}}+4.80\right) \mathrm{eV}$ or $E_{\mathrm{LUMO}}=-\left(E_{\mathrm{red}}{ }^{\text {onset }}-E_{\text {(ferrocene) }}{ }^{\text {onset }}+4.80\right) \mathrm{eV}$. The electrochemical data were collected in Table 1. As shown in Fig 3 (a), the $E_{\text {oxd }}{ }^{\text {onset }}$ of $\mathbf{3 a}, \mathbf{3 b}$ and $\mathbf{3 c}$ are 0.96 , 1.00 and $1.02 \mathrm{eV}$, respectively. Correspondingly, the HOMO energy levels are

calculated to be $-5.30 \mathrm{eV}$ for $\mathbf{3 a},-5.34 \mathrm{eV}$ for $\mathbf{3 b}$ and $-5.36 \mathrm{eV}$ for $\mathbf{3 c}$. The $E_{\text {red }}{ }^{\text {onset }}$ of the three molecules are $-1.09,-1.02$, and $-1.00 \mathrm{eV}$, and the LUMO energy levels of 3a, $\mathbf{3 b}$ and $\mathbf{3 c}$ are estimated to be $-3.25,-3.32$, and $-3.34 \mathrm{eV}$, respectively. With the incorporation of the $\mathrm{F}$ and $\mathrm{Cl}$ atoms on the $\pi$-conjugated backbones, both $\mathbf{3 b}$ and $\mathbf{3 c}$ show lower HOMO and LUMO energy levels. The HOMO level of DITVT-5Cl is slightly lower than that of DITVT-5F, which is consistent with the calculated values. The similar phenomenon could also be observed in isoindigo derivatives. The energy 
gaps $\left(E_{\mathrm{cv}}{ }^{\mathrm{g}}\right)$, calculated using the equation of $E_{\mathrm{cv}}{ }^{\mathrm{g}}=E_{\mathrm{LUMO}}-E_{\mathrm{HOMO}}$ are $2.05 \mathrm{eV}, 2.02$ $\mathrm{eV}$ and $2.02 \mathrm{eV}$ for 3a, 3b and 3c, respectively.

Thermal gravimetric analysis (Fig. 3(b)) was used to examine the thermal stabilities of the final compounds. The decomposition temperatures ( $T_{\mathrm{d}}$, with $5 \%$ weight loss) are over $350{ }^{\circ} \mathrm{C}$ for all the three semiconductor materials. These results indicate that the three compounds own high thermal stabilities. To further understand the thermal properties, differential scanning calorimetry (DSC) experiments were carried out of all the three compounds, and the corresponding curves were shown in Fig. S2. Apparently, 3a and 3b show sharp phase transition peak around $180{ }^{\circ} \mathrm{C}$, while $\mathbf{3 c}$ shows low phase transition peak around $205^{\circ} \mathrm{C}$. The difference of the phase transition temperatures implies they have different crystalline state among $\mathbf{3 a}, \mathbf{3 b}$ and $\mathbf{3 c}$.

\subsection{OFET Characteristics}

The OFET devices were fabricated with a bottom gate-bottom contact (BGBC) configuration to investigate the charge transport properties of the three materials. All the semiconducting thin films were prepared by spin coating method unless otherwise specified. The measured performances and the results are shown in Table 2. Typical output and transfer field-effect characteristics using $\mathbf{3 b}$ as the active semiconductor are presented in Fig 4. All the OFET devices exhibited typical p-type operation. For 3a, the annealed thin film afforded charge mobility of $0.023 \mathrm{~cm}^{2} \mathrm{~V}^{-1} \mathrm{~s}^{-1}$, mildly higher than $0.012 \mathrm{~cm}^{2} \mathrm{~V}^{-1}$ $\mathrm{s}^{-1}$ of as-spun thin film. For $\mathbf{3 b}$, however, the annealed thin film exhibited carrier mobility of $0.030 \mathrm{~cm}^{2} \mathrm{~V}^{-1} \mathrm{~s}^{-1}$, much higher than $0.009 \mathrm{~cm}^{2} \mathrm{~V}^{-1} \mathrm{~s}^{-1}$ of its 
as-spun thin film. For $\mathbf{3 c}$, the low mobilities of less than $10^{-3} \mathrm{~cm}^{2} \mathrm{~V}^{-1} \mathrm{~s}^{-1}$ were obtained in the films before and after annealing. Additionally, the highest hole mobility of $0.10 \mathrm{~cm}^{2} \mathrm{~V}^{-1} \mathrm{~s}^{-1}$ was obtained in thin film of $\mathbf{3 b}$ fabricated with drop-casting method. Thin films of the other two compounds, $\mathbf{3 a}$ and $\mathbf{3 c}$, were also characterized by drop-casting method, and the mobilities are $2.92 \times 10^{-2}$ $\mathrm{cm}^{2} \mathrm{~V}^{-1} \mathrm{~s}^{-1}$ and $2.33 \times 10^{-2} \mathrm{~cm}^{2} \mathrm{~V}^{-1} \mathrm{~s}^{-1}$, respectively, which are also higher than the corresponding values acquired by spin-coating method. The low evaporation rate of the solvent contributes to the crystallization, thus leads to the high mobility. These observations suggest that the annealing process is beneficial to molecular self-assembly, and the introduction of fluorine atoms on $\pi$-conjugated backbones is more favourable for obtaining efficient charge transport than that of chlorine atoms.

\subsection{Thin Film Microstructure Analyses}

To further understand the correlation between the microstructure and the device performance, X-ray diffraction (XRD) analyses were carried out. The corresponding XRD profiles are shown in Fig 5. No obvious diffraction peak is observed in the XRD patterns of as-spun films, meaning that the as-spun films of $\mathbf{3 a}, \mathbf{3 b}$ and $\mathbf{3 c}$ are amorphous state and own poor crystallinity. After annealing at optimized temperature (3a and $\mathbf{3 b}$ at $140{ }^{\circ} \mathbf{C}, \mathbf{3 c}$ at $\left.120{ }^{\circ} \mathbf{C}\right)$, strong and sharp diffraction peaks are observed for $\mathbf{3 a}$ and $\mathbf{3 b}$ thin films while a relatively low diffraction peaks are observed for $\mathbf{3 c}$. These results indicate that the annealed $\mathbf{3 a}$ and $\mathbf{3 b}$ thin films have more orderly packing and better 
crystallinity than that of $\mathbf{3 c}$ thin film. For the annealed $\mathbf{3 a}$ and $\mathbf{3 b}$ thin films, the strong reflection peaks locate at $2 \theta$ of $5.70^{\circ}$ and $5.93^{\circ}$, corresponding to the similar $d$-spacing of $15.49 \AA$ and $14.89 \AA$, respectively. On the other hand, the $d$-spacing of $\mathbf{3 c}$ is $21.02 \AA$. The difference of $d$-spacing implies that $\mathbf{3 a}$ and $\mathbf{3 b}$ adopt similar packing orientation on the substrate, whereas $3 \mathbf{c}$ conducts different packing mode. The X-ray diffraction (XRD) analyses are well correlated with the device performance of OFETs based on the three small molecules.

The thin film morphologies were characterized with atom force microscopy (AFM). As shown in Fig. S3. The as-spun thin films of $\mathbf{3 a}$ and $\mathbf{3 b}$ have small grains and large grain boundaries, while the counterpart of $\mathbf{3 c}$ does not show any grains. The grain boundaries would act as traps and capture the carriers, and are harmful to carrier mobility, thus lead to low mobility. After annealing at high temperature, the grain size of $\mathbf{3 a}$ and $\mathbf{3 b}$ thin films grew and the grain boundaries decreased, which are beneficial to charge transport in OFET devices. 3a shows disc-like grains while $\mathbf{3 b}$ exhibits dense sheet-like grains in their respective thin films. Notably, the annealed 3c thin film also displays small needle-like grains; nevertheless, large grain boundaries still exist. The characterization results imply that halogen atoms exert significant influence on tuning thin film crystallinity and morphology of organic semiconducting materials. More importantly, the introduction of the fluorine atoms has positive 
influence, inducing the resulting $\mathbf{3 b}$ to form dense, crystalline thin film with large grains and small grain boundaries.

\section{Conclusions}

In this work, we have synthesized three A-D-A type small molecules, in which (E)-1,2-di(thiophen-2-yl)ethene acts as the donor unit and indolin-2-ones act as the acceptor units. The emergence of $\mathrm{S} \cdots \mathrm{O}$ conformational locks is in favour of keeping $\pi$-conjugated backbones planarity of the three small molecules. The introduction of the halogen atom can effectively tune optical properties, frontier molecular orbital energy levels, thin films crystallinity and surface morphology. Especially, with the introduction of fluorine atoms, $\mathbf{3 b}$ affords higher charge mobility than those of $\mathbf{3 a}$ and 3c. The improved field-effect properties can be attributed to the better crystallinity, denser and more orderly molecular arrangement in annealed $\mathbf{3 b}$ thin film.

\section{Notes}

\$ Authors C. Y. Wei and J. B. Zou contributed equally to this work. The authors declare no competing financial interest.

\section{Acknowledgements}

This work was financially supported by the National Science Foundation of China (51473021, 21474116, and 51233006) and the Strategic Priority Research Program of the Chinese Academy of Sciences (XDB12030100).

\section{References}


[1] Li Y, Sonar P, Murphy L, Hong W. High mobility diketopyrrolopyrrole (DPP)-based organic semiconductor materials for organic thin film transistors and photovoltaics. Energy \& Environmental Science. 2013;6(6):1684-710.

[2] Wang L, Xie X, Shi S, Shi K, Mao Z, Zhang W, et al. Synthesis, characterization, and field-effect properties of (E)-2-(2-(thiophen-2-yl) vinyl) thiophen-based donor-acceptor copolymers. Polymer. 2015;68:302-7.

[3] Guo X, Facchetti A, Marks TJ. Imide- and Amide-Functionalized Polymer Semiconductors. Chemical Reviews. 2014;114(18):8943-9021.

[4] Steudel S, De Vusser S, Myny K, Lenes M, Genoe J, Heremans P. Comparison of organic diode structures regarding high-frequency rectification behavior in radio-frequency identification tags. Journal of Applied Physics. 2006;99(11):114519.

[5] Katz HE, Bao Z, Gilat SL. Synthetic Chemistry for Ultrapure, Processable, and High-Mobility Organic Transistor Semiconductors. Accounts of Chemical Research. 2001;34(5):359-69.

[6] Lakatos AI. Introduction. Journal of the Society for Information Display. 2000;8(1):1-1.

[7] Abe M, Mori T, Osaka I, Sugimoto K, Takimiya K. Thermally, Operationally, and Environmentally Stable Organic Thin-Film Transistors Based on Bis[1]benzothieno[2,3-d:2',3'-d']naphtho[2,3-b:6,7-b']dithiophene Derivatives: Effective Synthesis, Electronic Structures, and Structure-Property Relationship. Chemistry of Materials. 2015;27(14):5049-57. 
[8] Chen H, Guo Y, Yu G, Zhao Y, Zhang J, Gao D, et al. Highly $\pi$-Extended Copolymers with Diketopyrrolopyrrole Moieties for High-Performance Field-Effect Transistors. Advanced Materials. 2012;24(34):4618-22.

[9] Ashraf RS, Meager I, Nikolka M, Kirkus M, Planells M, Schroeder BC, et al. Chalcogenophene Comonomer Comparison in Small Band Gap Diketopyrrolopyrrole-Based Conjugated Polymers for High-Performing Field-Effect Transistors and Organic Solar Cells. Journal of the American Chemical Society. 2015;137(3):1314-21.

[10] Zhang W, Liu Y, Yu G. Heteroatom Substituted Organic/Polymeric Semiconductors and their Applications in Field-Effect Transistors. Advanced Materials. 2014;26(40):6898-904.

[11] Lei T, Cao Y, Zhou X, Peng Y, Bian J, Pei J. Systematic Investigation of Isoindigo-Based Polymeric Field-Effect Transistors: Design Strategy and Impact of Polymer Symmetry and Backbone Curvature. Chemistry of Materials. 2012;24(10):1762-70.

[12] Kang I, Yun H-J, Chung DS, Kwon S-K, Kim Y-H. Record High Hole Mobility in Polymer Semiconductors via Side-Chain Engineering. Journal of the American Chemical Society. 2013;135(40):14896-9.

[13] Mei J, Bao Z. Side Chain Engineering in Solution-Processable Conjugated Polymers. Chemistry of Materials. 2014;26(1):604-15.

[14] Lei T, Wang J-Y, Pei J. Roles of Flexible Chains in Organic Semiconducting Materials. Chemistry of Materials. 2014;26(1):594-603. 
[15] Zen A, Pflaum J, Hirschmann S, Zhuang W, Jaiser F, Asawapirom U, et al. Effect of Molecular Weight and Annealing of Poly(3-hexylthiophene)s on the Performance of Organic Field-Effect Transistors. Advanced Functional Materials. 2004;14(8):757-64.

[16] Leong WL, Welch GC, Kaake LG, Takacs CJ, Sun Y, Bazan GC, et al. Role of trace impurities in the photovoltaic performance of solution processed small-molecule bulk heterojunction solar cells. Chemical Science. 2012;3(6):2103-9.

[17] Abdou MSA, Lu X, Xie ZW, Orfino F, Deen MJ, Holdcroft S. Nature of Impurities in .pi.-Conjugated Polymers Prepared by Ferric Chloride and Their Effect on the Electrical Properties of Metal-Insulator-Semiconductor Structures. Chemistry of Materials. 1995;7(4):631-41.

[18] Anthony JE. The Larger Acenes: Versatile Organic Semiconductors. Angewandte Chemie International Edition. 2008;47(3):452-83.

[19] Liang Z, Tang Q, Xu J, Miao Q. Soluble and Stable N-Heteropentacenes with High Field-Effect Mobility. Advanced Materials. 2011;23(13):1535-9.

[20] Takimiya K, Osaka I, Mori T, Nakano M. Organic Semiconductors Based on [1]Benzothieno[3,2-b][1]benzothiophene Substructure. Accounts of Chemical Research. 2014;47(5):1493-502.

[21] Takimiya K, Shinamura S, Osaka I, Miyazaki E. Thienoacene-Based Organic Semiconductors. Advanced Materials. 2011;23(38):4347-70.

[22] Heeger AJ. Semiconducting polymers: the Third Generation. Chemical Society 
Reviews. 2010;39(7):2354-71.

[23] Li J, Zhao Y, Tan HS, Guo Y, Di C-A, Yu G, et al. A stable solution-processed polymer semiconductor with record high-mobility for printed transistors. Scientific Reports. 2012;2:754.

[24] Cai Z, Guo Y, Yang S, Peng Q, Luo H, Liu Z, et al. New Donor-Acceptor-Donor Molecules with Pechmann Dye as the Core Moiety for Solution-Processed Good-Performance Organic Field-Effect Transistors. Chemistry of Materials. 2013;25(3):471-8.

[25] Lei T, Dou J-H, Cao X-Y, Wang J-Y, Pei J. Electron-Deficient Poly(p-phenylene vinylene) Provides Electron Mobility over $1 \mathrm{~cm}^{2} \mathrm{~V}^{-1} \mathrm{~s}^{-1}$ under Ambient Conditions. Journal of the American Chemical Society. 2013;135(33):12168-71.

[26] Bromley ST, Mas-Torrent M, Hadley P, Rovira C. Importance of Intermolecular Interactions in Assessing Hopping Mobilities in Organic Field Effect Transistors: Pentacene versus Dithiophene-tetrathiafulvalene. Journal of the American Chemical Society. 2004;126(21):6544-5.

[27] Schmidt R, Oh JH, Sun Y-S, Deppisch M, Krause A-M, Radacki K, et al. High-Performance Air-Stable n-Channel Organic Thin Film Transistors Based on Halogenated Perylene Bisimide Semiconductors. Journal of the American Chemical Society. 2009;131(17):6215-28.

[28] Tang ML, Bao Z. Halogenated Materials as Organic Semiconductors. Chemistry of Materials. 2011;23(3):446-55.

[29] Xin Zhang J, Dubois P, Jerome R. Synthesis of novel conjugated oligomers for 
second-order nonlinear optics: incorporation of a central spacer as a conjugation modulator. Journal of the Chemical Society, Perkin Transactions 2. 1997(6):1209-16.

[30] Hahn L, Maaß F, Bleith T, Zschieschang U, Wadepohl H, Klauk H, et al. Core Halogenation as a Construction Principle in Tuning the Material Properties of Tetraazaperopyrenes. Chemistry - A European Journal. 2015;21(49):17691-700.

[31] Hiszpanski AM, Saathoff JD, Shaw L, Wang H, Kraya L, Lüttich F, et al. Halogenation of a Nonplanar Molecular Semiconductor to Tune Energy Levels and Bandgaps for Electron Transport. Chemistry of Materials. 2015;27(5):1892-900.

[32] Tang ML, Oh JH, Reichardt AD, Bao Z. Chlorination: A General Route toward Electron Transport in Organic Semiconductors. Journal of the American Chemical Society. 2009;131(10):3733-40. 
Table 1. Electrochemical and optical properties of all the compounds $\mathbf{3 a}, \mathbf{3 b}$ and $\mathbf{3 c}$.

\begin{tabular}{|c|c|c|c|c|c|c|c|c|c|}
\hline \multirow{2}{*}{ compd } & \multirow{2}{*}{$\begin{array}{c}E_{\mathrm{ox}}{ }^{\text {oneset }} \\
(\mathrm{V})\end{array}$} & \multirow{2}{*}{$\begin{array}{c}E_{\text {red }}^{\text {oneset }} \\
\text { (V) }\end{array}$} & \multirow{2}{*}{$\begin{array}{c}E_{\mathrm{HOMO}} / E(\mathrm{cal}) \\
\mathrm{eV}\end{array}$} & \multirow{2}{*}{$\begin{array}{c}E_{\mathrm{LUMO}} / E(\mathrm{cal}) \\
\mathrm{eV}\end{array}$} & \multirow{2}{*}{$\begin{array}{l}E_{\mathrm{cv}}{ }^{\mathrm{g}} \\
(\mathrm{eV})\end{array}$} & \multicolumn{2}{|c|}{$\lambda_{\max }(\mathrm{nm})$} & \multirow{2}{*}{$\begin{array}{l}E_{\mathrm{opt}^{\mathrm{g}}} \\
(\mathrm{eV})\end{array}$} & \multirow{2}{*}{$\varepsilon\left(\mathrm{M}^{-1} \mathrm{~cm}^{-1}\right)$} \\
\hline & & & & & & solution & film & & \\
\hline 3a & 0.96 & -1.09 & $-5.30 /-5.22$ & $-3.25 /-2.93$ & 2.05 & 516 & 531 & 1.88 & $4.11 \times 10^{4}$ \\
\hline $3 \mathbf{b}$ & 1.00 & -1.02 & $-5.34 /-5.39$ & $-3.32 /-3.11$ & 2.02 & 522 & 573 & 1.81 & $6.95 \times 10^{4}$ \\
\hline $3 c$ & 1.02 & -1.00 & $-5.36 /-5.41$ & $-3.34 /-3.14$ & 2.02 & 530 & 547 & 1.85 & $6.42 \times 10^{4}$ \\
\hline$E_{\mathrm{HOMO}}=$ & $\left(E_{\text {oxd }^{\circ}}{ }^{-}\right.$ & errocer & $+4.8) \mathrm{eV}$, & $\mathrm{MO}=-\left(E_{\mathrm{rec}}\right.$ & $E$ & e) ${ }^{\text {onset }}$ & 10 & $=$ & мо $-E_{\text {номо }}$ \\
\hline
\end{tabular}

Table 2. The sum of the OFETs performance of the compounds $\mathbf{3 a}, \mathbf{3 b}$ and $\mathbf{3 c}$

\begin{tabular}{ccccc}
\hline Compd & $T_{\text {an }} /{ }^{\circ} \mathrm{C}$ & $\mu_{\mathrm{h}} / \mathrm{cm}^{2} \mathrm{v}^{-1} \mathrm{~s}^{-1}$ & $I_{\text {on } / \mathrm{ff}}$ & $V_{\mathrm{T}}(\mathrm{V})$ \\
\hline 3a & 25 & 0.012 & $10^{5}-10^{6}$ & $0-10$ \\
& 140 & 0.023 & $10^{6}-10^{7}$ & $0-10$ \\
$\mathbf{3 b}$ & 25 & $9.10 \times 10^{-3}$ & $10^{6}-10^{7}$ & $-10-0$ \\
& 140 & 0.030 & $10^{6}-10^{7}$ & $-10-0$ \\
$\mathbf{3 c}$ & 25 & $4.00 \times 10^{-5}$ & $10^{4}-10^{5}$ & -10 \\
& 120 & $4.50 \times 10^{-3}$ & $10^{5}-10^{6}$ & -20 \\
\hline
\end{tabular}




\section{Figure Captions}

Scheme 1. The chemical structures and synthetic routes of the compounds $\mathbf{3 a}, \mathbf{3 b}$ and $3 c$.

Fig 1. The calculated energy levels and distribution of HOMOs and LUMOs of the compounds $\mathbf{3 a}, \mathbf{3 b}$ and $\mathbf{3 c}$.

Fig 2. UV-vis absorption spectra of the compounds $\mathbf{3 a}, \mathbf{3 b}$ and $\mathbf{3 c}$ in chloroform solution (a) and in the thin films (b).

Fig 3. The cyclic voltammograms (a) and thermal properties (b) of the compounds 3a, 3b and 3c.

Fig 4. The output (left) and transfer (right) characteristics of OFET devices based on the compound $\mathbf{3 b}$.

Fig 5. X-ray diffraction patterns at room temperature (RT) and heated in different temperature of the compounds $\mathbf{3 a}, \mathbf{3 b}$ and $\mathbf{3 c}$. The data in parenthesis is the corresponding temperature. 


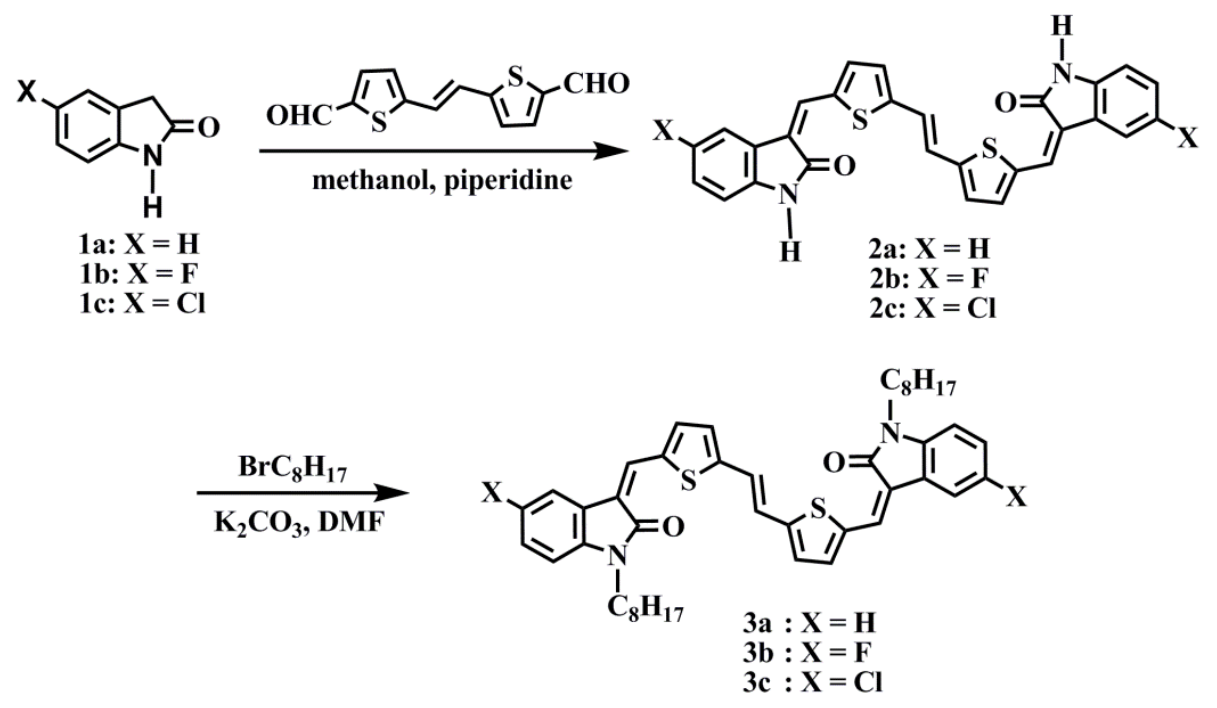

Scheme 1. The chemical structures and synthetic routes of the compounds $\mathbf{3 a}, \mathbf{3 b}$ and $\mathbf{3 c}$.

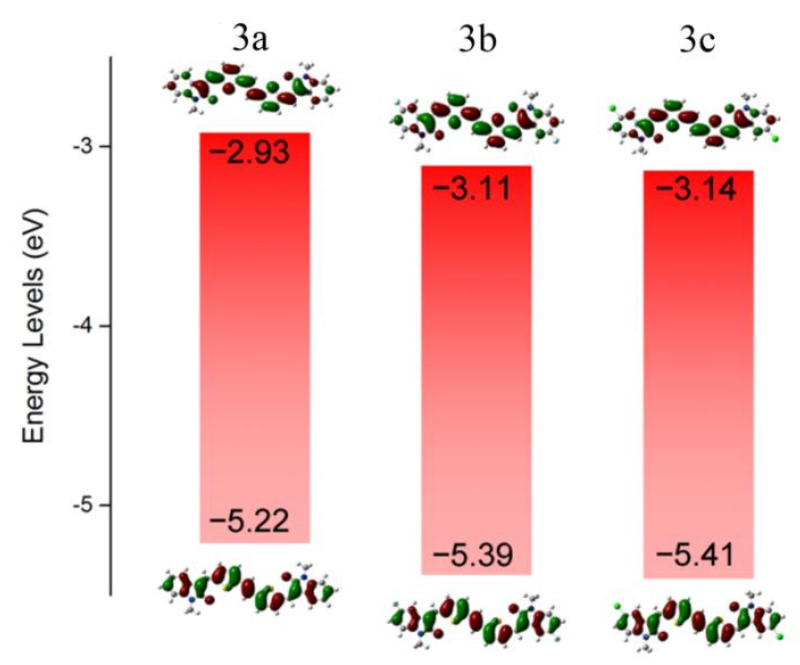

Fig. 1. The calculated energy levels and distribution of HOMOs and LUMOs of the compounds

3a, $\mathbf{3 b}$ and $\mathbf{3 c}$. 

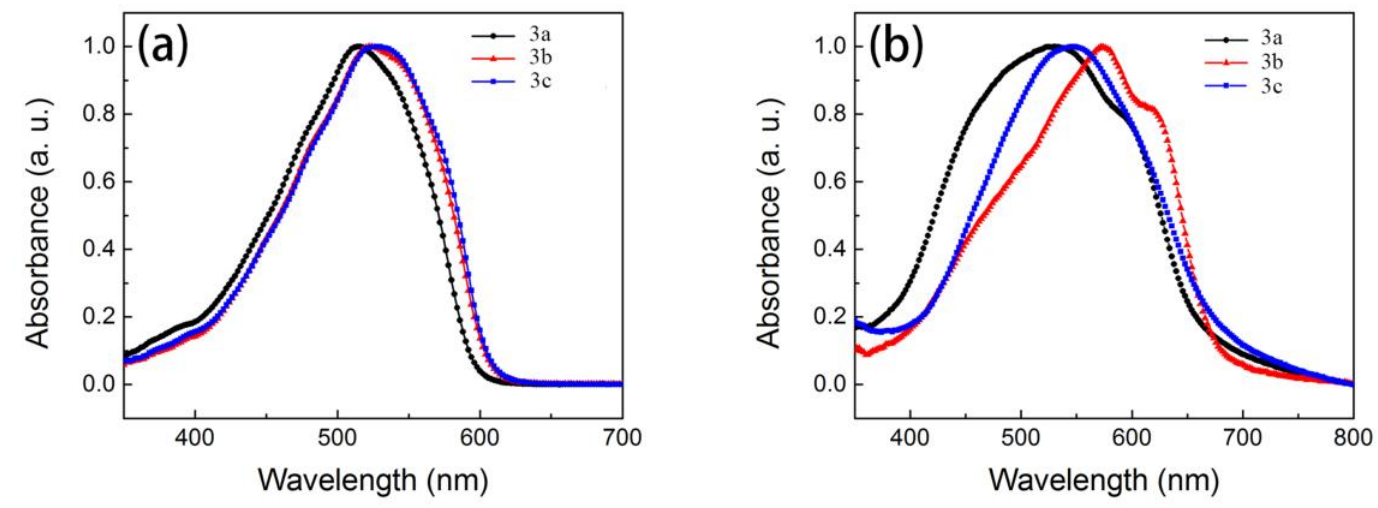

Fig. 2. UV-vis absorption spectra of the compounds $\mathbf{3 a}, \mathbf{3 b}$ and $\mathbf{3 c}$ in chloroform solution (a) and in the thin films (b).
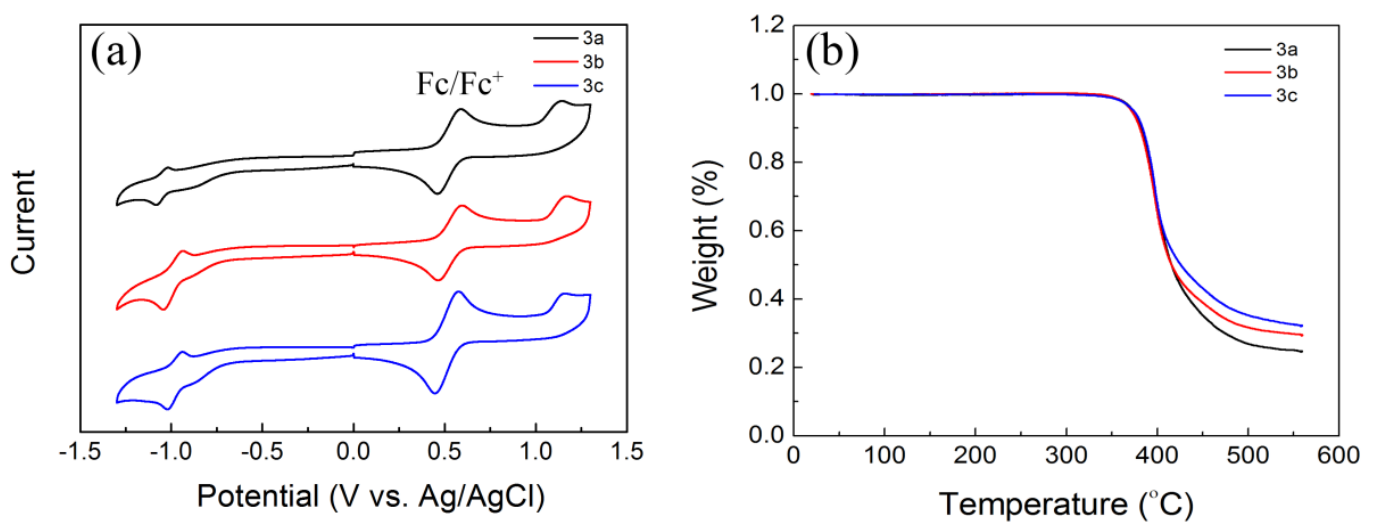

Fig. 3. The cyclic voltammograms (a) and thermal properties (b) of the compounds $\mathbf{3 a}, \mathbf{3 b}$ and $\mathbf{3 c}$.
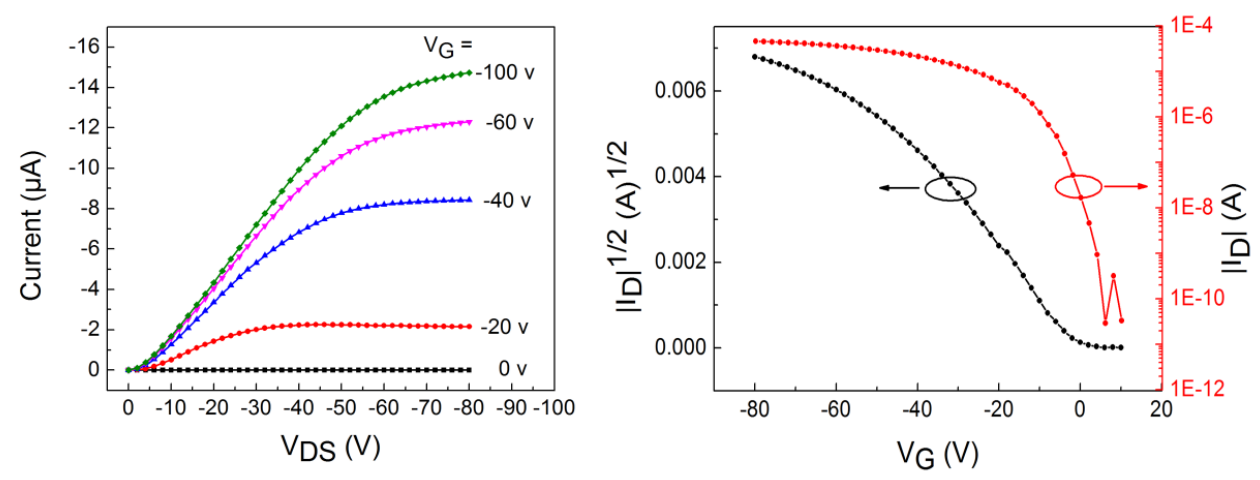

Fig. 4. The output (left) and transfer (right) characteristics of OFET devices based on the compound $\mathbf{3 b}$. 


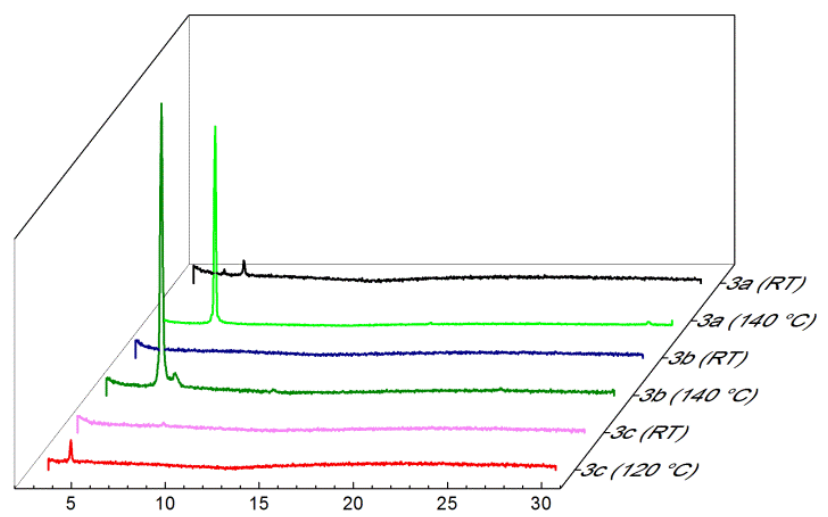

Fig. 5. X-ray diffraction patterns at room temperature (RT) and heated in different temperature of the $\mathbf{3 a}, \mathbf{3} \mathbf{b}$ and $\mathbf{3 c}$ thin films. The data in parenthesis is the corresponding annealing temperature. 